\title{
Kenya: Offer family planning on hospital wards
}

Frontiers in Reproductive Health

Follow this and additional works at: https://knowledgecommons.popcouncil.org/departments_sbsr-rh

Part of the Health Services Research Commons, International Public Health Commons, and the Women's Health Commons

How does access to this work benefit you? Let us know!

\section{Recommended Citation}

"Kenya: Offer family planning on hospital wards," FRONTIERS OR Summary. Washington, DC: Population Council, 2000. 


\section{Kenya \\ Postabortion \\ Care}

\section{OR Summary 5}

\section{Offer Family Planning on Hospital Wards}

The most effective way to ensure that women being treated for incomplete abortion obtain family planning is to offer information and services in hospital gynecological wards, this study concluded. Having ward staff provide contraceptives on the ward is more convenient than having regular family planning providers visit the ward or having patients go to a separate clinic. Findings from this study have been key in informing the expansion plan for PAC in Kenya.

\section{Background}

In Kenya, more than one in three women hospitalized for gynecological problems have complications from miscarriage or unsafe abortion. These women generally receive no information or services for family planning or other reproductive health needs.

During 1996-1997, the Kenya Ministry of Health $(\mathrm{MOH})$, Population Council and Ipas collaborated to test three models for providing postabortion care (PAC) and family planning (FP) information and services in two areas of the hospital. The three models are: (1) having gynecology ward staff provide postabortion FP services on the ward; (2) having staff from the maternal and child health/FP clinic provide FP on the gynecology ward; and (3) providing FP at the $\mathrm{MCH} / \mathrm{FP}$ clinic after PAC treatment but before hospital discharge. Six large district and provincial hospitals served as pilot sites.

Researchers compared the effectiveness of the three models by using surveys given before (481 patients and 140 providers) and after the intervention (319 patients, 92 male partners of patients, and 106 providers).

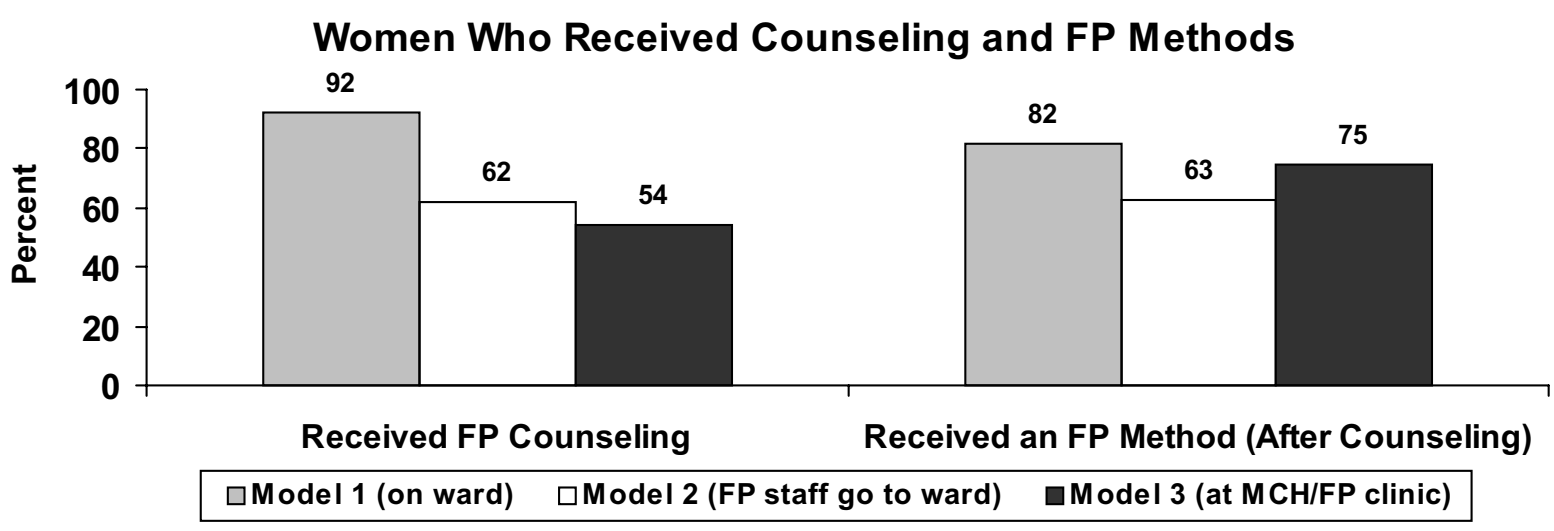


The intervention consisted of: (1) training doctors and nurses in manual vacuum aspiration (MVA) and postabortion FP; (2) providing equipment and supplies; and (3) reorganizing services to better suit patients' needs. All pilot sites designated small rooms for MVA procedures, thus speeding up patient flow and freeing up the main operating rooms. The hospitals offering FP services created private counseling areas on the wards by converting unused space, adding partitions, or reorganizing space. They obtained contraceptive supplies from the hospital's MCH/FP clinic.

\section{Findings}

- Model 1 - providing postabortion FP information and services on the ward - led to increased adoption of contraception and shorter hospital stays. Under Model 1 , more patients actually received FP counseling and services than in the other two models (see graph).

- Providers and patients reacted positively to the improved PAC services offered in all three models. Providers preferred MVA to pre-intervention clinical treatment methods. Before the package was introduced, only 7 percent of all PAC patients received FP counseling, compared with 68 percent after the intervention.

- In all settings PAC services could be further improved by providing patients with more information. Only 16 percent of the patients were told what to do if problems developed. Similarly, only 41 percent of the patients were warned that they could conceive again soon after abortion. Roughly half of the patients were told about the possible side effects of their chosen method.

- Pain control practices remain a problem. Only 3 percent of the patients in both the baseline and post-intervention groups received pain medication, and thus nearly all women reported pain during treatment.

- Husbands/partners of patients indicated a strong interest in receiving more information from providers. More than 90 percent of the men interviewed said that they would have liked to know more about their wife/partner's condition and family planning. One hospital began to counsel couples on the gynecological ward.

\section{Policy Implications}

- Postabortion FP information and services should be offered on gynecological wards by ward staff. Ward staff may need additional training in FP counseling.

- Men accompanying PAC patients should also be offered information on their partner's condition and FP counseling, if the woman consents.

- PAC providers must provide medication for pain control and should not rely on verbal reassurances alone.

To ensure that PAC services continue, hospital administrators need to ensure that staff are adequately trained and that equipment, supplies, and drugs are available. Both pre-service and inservice training are needed to integrate PAC skills into the existing health system.

\section{- Based on these findings, the Kenya $\mathrm{MOH}$ developed detailed workplans for expansion of improved PAC services. These plans have now been incorporated into a national strategy to expand PAC throughout Kenya, in both the public and private sector.}

February 2000

Solo, Julie, et al. 1998. Creating Linkages between Incomplete Abortion Treatment and Family Planning Services in Kenya: What Works Best? Also see Improving Care of Postabortion Patients in Hospitals, OR Summaries, January 1998. For more information, contact: Population Council, P.O. Box 17643, Nairobi, Kenya.Tel.254-2-713-480; Fax: 254-2-713-479; E-mail: publications@popcouncil.or.ke.

This project was conducted with support from the U.S. AGENCY FOR INTERNATIONAL DEVELOPMENT under Contract Number CCP-3030-C-00-3008-00 and Cooperative Agreement Number HRN-A-00-98-00012-00. 